IZA DP No. 3637

\title{
Does Private Tutoring Payoff?
}

Ayfer Gurun

Daniel L. Millimet

August 2008 


\title{
Does Private Tutoring Payoff?
}

\author{
Ayfer Gurun \\ Southern Methodist University \\ Daniel L. Millimet \\ Southern Methodist University \\ and IZA

\section{Discussion Paper No. 3637 \\ August 2008} \\ IZA \\ P.O. Box 7240 \\ 53072 Bonn \\ Germany \\ Phone: +49-228-3894-0 \\ Fax: +49-228-3894-180 \\ E-mail: iza@iza.org
}

Any opinions expressed here are those of the author(s) and not those of IZA. Research published in this series may include views on policy, but the institute itself takes no institutional policy positions.

The Institute for the Study of Labor (IZA) in Bonn is a local and virtual international research center and a place of communication between science, politics and business. IZA is an independent nonprofit organization supported by Deutsche Post World Net. The center is associated with the University of Bonn and offers a stimulating research environment through its international network, workshops and conferences, data service, project support, research visits and doctoral program. IZA engages in (i) original and internationally competitive research in all fields of labor economics, (ii) development of policy concepts, and (iii) dissemination of research results and concepts to the interested public.

IZA Discussion Papers often represent preliminary work and are circulated to encourage discussion. Citation of such a paper should account for its provisional character. A revised version may be available directly from the author. 
IZA Discussion Paper No. 3637

August 2008

\section{ABSTRACT}

\section{Does Private Tutoring Payoff?}

We assess the causal effect of private tutoring on the probability of university placement in Turkey. We find that tutoring increases the probability of being placed in a university when non-random selection is ignored. Moreover, among those utilizing private tutoring, greater expenditure on tutoring is also positively associated with university placement. However, we find evidence of positive selection into tutoring, but negative selection into greater expenditures among those receiving tutoring. Accounting for this pattern of non-random selection, we conclude that private tutoring has a negative causal effect on university placement overall, but conditional on receiving any tutoring, spending more on tutoring has a positive causal effect on university placement.

JEL Classification: C31, H51, I21, O15

Keywords: tutoring, Turkey, tertiary education, program evaluation

Corresponding author:

Daniel L. Millimet

Department of Economics

Southern Methodist University

Box 0496

Dallas, TX 75275-0496

USA

E-mail:millimet@mail.smu.edu

\footnotetext{
* We thank Turkish Higher Education Council for providing us the data used in this study. All errors are our own.
} 


\section{Introduction}

The evolution of private tutoring - fee-based tutoring outside the normal school day that provides supplementary instruction to students in academic subjects - has proliferated around the world. It became popular initially in Asia several decades ago, and has since spread to Africa, Europe, and North America (Dang and Rogers 2008). ${ }^{1}$ This growth has encountered mixed reactions from policymakers and educational researchers. First and foremost, it is unclear if private tutoring has a beneficial, causal effect on academic achievement. Second, if it does, this raises concerns regarding educational equity and limitations on intergenerational income mobility. Finally, private tutoring, particularly when it is done by teachers outside of school, creates an incentive for teachers to provide lower quality education within the public school system. In this study, we exploit a unique database from Turkey to examine the first and second concerns.

Bray and Kwok (2003) and Bray (1999) review private tutoring schemes across a diverse set of countries. One stylized fact is that private tutoring is more common in countries with competitive university entrance examinations (Tansel and Bircan 2006). In many countries, the combination of these high stakes exams and shortcomings of the educational system (e.g., insufficient supply of universities, large class sizes, and inadequate public resources) are also mentioned as salient factors underlying the demand for private tutoring (Tansel and Bircan 2006). Moreover, demand for private tutoring is not solely confined to developing countries (Bray and Kwok 2003). Here, the poor performance by students on international achievement tests is given as a contributing factor to the growth in demand.

In Turkey, the government is responsible for providing formal education at all levels, including the compulsory level (primary and secondary school) and high school. ${ }^{2}$ There does exist an active private sector in formal education especially in urban areas. Public and private schools are governed by the Ministry of Education. Due to a limited supply of tertiary education, a national university entrance exam is required of all high school graduates to gain access to university education.

The demand for private tutoring in Turkey emanates from the competitive university placement examination (Tansel and Bircan 2006). There exist three types of private tutoring in Turkey: (i) one-on-one instruction by a privately paid teacher, (ii) formal courses offered by teachers after regular school hours, and (iii) private firms offering lessons by professional teachers in a classroom setting. Although the first and second types are frequently utilized, they are not regulated. The third type is the most common; facilities of this exist across the country (Tansel and Bircan 2006). Students attend these facilities outside the regular school day, and they are noted for smaller classes, improved class materials, and more effective student-teacher interactions compared to formal schools (Tansel and Bircan 2006).

The number of private tutoring centers has proliferated over the past two decades (Tansel and Bircan 2006). In 1984 there were less than 200 such centers across the country. After a 1984 legal reform recognizing

\footnotetext{
${ }^{1}$ Surveys covering the extent of private tutoring in selected countries can be found in Dang (2007a, b) and Dang and Rogers (2008).

${ }^{2}$ See Tansel and Bircan (2006) for a detailed review of the educational setup in Turkey. Tansel and Bircan (2008) provide a detailed account of the history of private tutoring centers.
} 
these private tutoring centers as part of educational activities, the number of centers quickly grew, reaching more than 2,000 in 2002 (Private Tutoring Centers Association 2003). For comparison, there were roughly 2,500 high schools in Turkey at the time (Ministry of Education of Turkey 2003).

The average fee charged by private tutoring centers in preparation for the university entrance examination was approximately $\$ 1,300$ US dollars in 2002 (Tansel and Bircan 2006). For comparison, per capita income in Turkey was 2,500 US dollars in 2002. Aggregate tutoring expenditures correspond to $1.44 \%$ of GDP, or $\$ 263$ million US dollars, and is comparable to total public sector educational spending (Tansel and Bircan 2006).

To understand the determinants of private tutoring, and its impact on university placement, we use survey data administrated by the Turkish Higher Education Council in 2002 merged with data on actual test outcomes. More than ten percent of the 1.2 million students taking the 2002 university entrance exam were required to complete the survey. The survey contains information on demographic attributes, educational background, and private tutoring. These data allow us to investigate two interesting issues. First, how effective is tutoring in gaining university placement? Second, who invests in tutoring?

Our analysis complements several existing studies using data from Turkey and elsewhere. Tansel and Bircan (2006) analyze expenditures on private tutoring in Turkey utilizing cross-sectional data from 1994. Kim and Lee (2004) similarly analyze expenditures in South Korea using two data sets from 1997 and 1998. Tansel and Bircan (2005) utilize the same data set as we do and assess the association between private tutoring and university placement and test scores in Turkey. The authors conclude that private tutoring is beneficial, but the treatment of tutoring as exogenous is suspect. Kang (2007) assesses the effect of private tutoring in South Korea on student academic achievement. The author attempts to circumvent the potential endogeneity of tutoring using an indicator for first born status as an instrument. While the instrument is fairly strong, birth order may directly affect academic achievement. Nonetheless, the effect of tutoring is imprecisely measured and not statistically significant. Finally, Dang (2007b) uses data from Vietnam in the 1990s to analyze determinants of private tutoring demand and its impact on academic achievement. The author utilizes the cost of tutoring charged by schools as an exclusion restriction, finding a positive effect of tutoring on academic performance.

In light of these previous studies, it is seems prudent to assess the role of non-random selection into tutoring in Turkey prior to inferring a causal effect of tutoring in that country. There are several reasons why we should be concerned about selection on unobservables in the Turkish case. As in South Korea and Vietnam, students receiving private tutoring may differ along various unobserved, but salient, dimensions from those who abstain from tutoring. For example, parents who purchase tutoring for their children may also aid their children's academic success in other ways (e.g., helping with homework). In addition, more motivated students may be more willing to enroll in private tutoring than their less motivated peers, and this motivation may translate into better academic performance even absent tutoring. However, the selection process may also work in the opposite direction. For example, students attending lower quality high schools, 
or who otherwise anticipate not performing well on the university placement exam, may be more willing to incur the cost of private tutoring.

Unfortunately, however, there does not seem to be any valid exclusion restriction in our data. To proceed, then, we employ several recently developed parametric and semi-nonparametric techniques from the program evaluation literature. These techniques allow us to assess the impact of non-random selection on the estimated treatment effects obtained under exogeneity. Our results show that non-random selection is an important issue. First, we find evidence of positive selection into private tutoring in general, but negative selection into high expenditure on tutoring. Second, a modest amount of positive selection on unobservables into tutoring is sufficient to explain the positive association between tutoring and university placement; in fact, the treatment effect actually becomes negative and statistically significant. However, the positive association between high expenditure on tutoring and university placement is robust to the presence of selection on unobservables. Since it is only high expenditure on tutoring that pays off, our results have significant ramifications for thinking about the current education system in Turkey, educational equity and intergenerational mobility. The remainder of the paper is organized as follows. Section 2 discusses the empirical framework and data. Section 3 presents the results. Section 4 concludes.

\section{Empirics}

\subsection{Data}

We use a survey administrated by the Turkish Higher Education Council in 2002 to more than ten percent of the 1.2 million students taking the 2002 university entrance exam. Our sample includes 90,410 students taking the exam for the first time. We focus on first-time test takers since the factors influencing the university placement of students taking the exam multiple times may be influenced by other factors that are not applicable to first-time takers.

We use placement to a university after the exam as our measure of academic achievement. We define two binary treatment variables. The first treatment variable, denoted Tutor I, takes on a value of one if the student receives any private tutoring prior to the exam (zero otherwise). The second treatment variable - denoted Tutor II and defined only for the subset of students receiving any private tutoring - takes on a value of one if the student spent more than $\$ 1,275$ US dollars on private tutoring prior to the exam, and a value of zero if the student spent less than $\$ 1,275$ (but more than zero). ${ }^{3}$ Thus, the first treatment allows us to assess the overall impact of private tutoring, while the second treatment allows to assess the impact of greater expenditure on private tutoring conditional on receiving any tutoring.

To control for parental and environmental factors, we include a number of covariates in the analysis. Categorical variables are included for the number of siblings, mother's and father's education, family income, primary and secondary test scores, and city population. In addition, dummy variables are included for gender

\footnotetext{
${ }^{3}$ This corresponds to amount greater than 1 Billion Turkish Liras in 2002.
} 
and internet access. ${ }^{4}$ We exclude students with missing data for gender. Missing values for the remaining control variables are imputed (replaced by zero) and imputation dummies are added to the control set. ${ }^{5}$

Summary statistics are provided in Table 1. In our sample of 90,410 students, $80.1 \%$ received private tutoring. Of these, 46,262 indicated a monetary amount, with $13.1 \%$ spending more than $\$ 1,275$ US dollars. Given the relatively high percentage of observations with missing data on total expenditures on private tutoring, one should be concerned with the representativeness of the sample when analyzing the second treatment. Thus, Table 1 provides separate summary statistics for individuals with Tutor II missing versus non-missing, as well as the p-values from $t$-tests of equal means. The results indicate that students with non-missing data clearly differ in a statistically and economically meaningful way from those with missing data. For example, students with missing data are much less likely to have internet access and high previous academic achievement; they are more likely to reside in less affluent households as measured by income and parental education, have more siblings, and reside in less populous areas. While we can control for these regressors in the analysis, it is likely that students with missing data also differ along unobservable dimensions as well. As such, the results using the Tutor II treatment should be interpreted cautiously. We shall return to this below.

\subsection{Methodology}

\subsubsection{Parametric Estimation}

We begin by specifying the following regression model

$$
y_{i}=\mathrm{I}\left(x_{i} \beta+\tau D_{i}+\varepsilon_{i}>0\right)
$$

where $y$ is a binary measure of observed university placement, $x$ is a vector of controls, $D$ represents one of the treatments being analyzed, $\beta$ and $\tau$ are parameters to be estimated, with $\tau$ being the parameter of primary interest, and $\varepsilon$ is the error term. Probit estimation of (1) yields a consistent estimate of $\tau$ if, conditional on $x, \operatorname{Cov}(D, \varepsilon)=0$ and $\varepsilon_{i} \stackrel{i i d}{\sim} N(0,1)$.

Even if the distributional assumption concerning $\varepsilon$ is correct, it is well known that $D$ and $\varepsilon$ will not be independent conditional on $x$ if individuals select into the treatment on the basis of unobservable attributes. The standard approach to so-called selection on unobservables is to utilize instrumental variables. However, in the current context, it is unlikely that there are any valid exclusion restrictions in the data. Instead, we borrow various strategies from the program evaluation literature to assess the sensitivity of our probit estimates to selection on unobservables. To assess the impact of non-random selection into tutoring, we

\footnotetext{
${ }^{4}$ Number of siblings takes values between one and five, where five represents "more than five siblings." Mother's and father's education each take values between one (no education) and seven (Master's/Ph.d.), where higher values indicate more education. Family income takes values between one (lowest) and seven (highest). Primary and secondary school test scores each take values between one (highest) and four (lowest). Finally, city population takes values between one (smallest) to nine (largest).

${ }^{5}$ Number of siblings and family income are missing for less than $1 \%$ of the sample; primary and secondary test scores are missing for less than $4 \%$ of the sample; mother's and father's education are missing for $6 \%$ and $8 \%$ of the sample, respectively; and, population is missing for $8 \%$ of the sample.
} 
employ the bivariate probit model utilized in Altonji et al. (2005, 2008). The model is given by

$$
\begin{aligned}
y_{i} & =\mathrm{I}\left(x_{i} \beta+\tau D_{i}+\varepsilon_{i}>0\right) \\
D_{i} & =\mathrm{I}\left(x_{i} \lambda+v_{i}>0\right)
\end{aligned}
$$

where $v$ is the error term in the treatment assignment equation.

Bivariate probit estimation of (2) yields a consistent estimate of $\tau$ if, conditional on $x, \varepsilon_{i}, v_{i} \stackrel{i i d}{\sim} N_{2}(0,0,1,1, \rho)$. The correlation coefficient, $\rho$, captures the correlation between unobservables that impact university placement and the likelihood of receiving the treatment; $\rho>0(\rho<0)$ implies positive (negative) selection on unobservables. Aside from the estimate of $\tau$, estimates of $\lambda$ and $\rho$ provide information on who receives private tutoring.

Given the bivariate normality assumption, the model is technically identified even absent an exclusion restriction; semi-parametric alternatives require an exclusion restriction. As such, to assess the role of selection into treatment without formally relying on the distributional assumption, Altonji et al. (2005, 2008) treat the model as underidentified by one parameter, $\rho$. Then, the authors constrain $\rho$ to different values and examine the estimates of the remaining parameters; constraining $\rho$ to be zero yields estimates under selection on observables only. We proceed along similar lines.

\subsubsection{Semi-Nonparametric Estimation}

The preceding estimator requires one to specify a functional form for the outcome equation, as well as distributions for the error terms. To relax these assumptions, we turn to two related, but distinct, seminonparametric estimation techniques. To understand both techniques, it is useful to explicitly consider the potential outcomes framework (see, e.g., Neyman 1923; Fisher 1935; Roy 1951; Rubin 1974). Let $y_{1 i}$ denote the potential outcome (i.e., university placement) of student $i$ under the treatment $(D=1) ; y_{0 i}$ denotes the potential outcome absent the treatment $(D=0)$. The student-specific causal effect of the treatment is given by the difference between the corresponding potential outcomes, $\tau_{i}=y_{1 i}-y_{0 i}$; the average treatment effect (ATE) is given by $\tau_{A T E}=\mathrm{E}\left[\tau_{i}\right]$.

For each student, the observed outcome, $y_{i}$, is equivalent to $y_{i}=D_{i} y_{1 i}+\left(1-D_{i}\right) y_{0 i}$. Thus, some identifying assumptions are needed to circumvent the missing counterfactual problem. Under the conditional independence assumption (CIA), treatment assignment is assumed to be independent of potential outcomes conditional on the set of observed covariates, $x$. Rosenbaum and Rubin (1983) show that independence conditional on $x$ implies independence conditional on the propensity score, $p\left(x_{i}\right)=\operatorname{Pr}\left(D_{i}=1 \mid x_{i}\right)$.

Two popular classes of propensity score-based estimators of the ATE under the CIA are weighting estimators and matching estimators. ${ }^{6}$ Because selection into treatment on the basis of unobservables will bias estimates of the ATE under either type of estimator, both of the estimation techniques below assess the

\footnotetext{
${ }^{6}$ In addition, such estimators also require the common support assumption whereby $p(x) \in(0,1)$ for all $x$.
} 
sensitivity of the estimates obtained under CIA to violations of this assumption. Thus, the logic is identical to the Altonji et al. $(2005,2008)$ approach discussed above in the context of parametric estimation.

Minimum Bias Inverse Propensity Score Weighting Our first estimation approach applies the technique recently proposed in Millimet and Tchernis (2008), who build on Black and Smith (2004). Intuitively, the idea is to utilize a weighting estimator applied to a properly chosen sub-set of the original sample in order to minimize the bias arising from failure of the CIA.

To begin, Hirano and Imbens (2001) propose the following (normalized) weighting estimator of the ATE:

$$
\hat{\tau}_{H I}=\left[\sum_{i=1}^{N} \frac{y_{i} D_{i}}{\widehat{p}\left(x_{i}\right)} / \sum_{i=1}^{N} \frac{D_{i}}{\widehat{p}\left(x_{i}\right)}\right]-\left[\sum_{i=1}^{N} \frac{y_{i}\left(1-D_{i}\right)}{1-\widehat{p}\left(x_{i}\right)} / \sum_{i=1}^{N} \frac{\left(1-D_{i}\right)}{1-\widehat{p}\left(x_{i}\right)}\right]
$$

where $\widehat{p}\left(x_{i}\right)$ is an estimate of the propensity score (obtain, for example, using a probit model). This estimator yields an unbiased estimate of $\tau_{A T E}$ under CIA. To examine the bias when CIA fails, assume the following:

(A1) Potential outcomes and latent treatment assignment are additively separable in observables and unobservables

$$
\begin{aligned}
y_{0} & =g_{0}(x)+\varepsilon_{0} \\
y_{1} & =g_{1}(x)+\varepsilon_{1} \\
D^{*} & =h(x)-v \\
D & = \begin{cases}1 & \text { if } D^{*}>0 \\
0 & \text { otherwise }\end{cases}
\end{aligned}
$$

(A2) $\varepsilon_{0}, \varepsilon_{1}, v \sim N_{3}(0, \Sigma)$, where

$$
\Sigma=\left[\begin{array}{ccc}
\sigma_{0}^{2} & \rho_{01} & \rho_{0 v} \\
& \sigma_{1}^{2} & \rho_{1 v} \\
& & 1
\end{array}\right] .
$$

Under (A1) and (A2), Millimet and Tchernis (2008) show that the bias of the ATE, conditional on $p(x)$, due to failure of the CIA is given by

$$
\begin{aligned}
B_{A T E}[p(x)] & =\rho_{0 v} \sigma_{0}\left\{\frac{\phi(h(x))}{\Phi(h(x))[1-\Phi(h(X))]}\right\}+[1-\Phi(h(x))]\left\{\rho_{\delta u} \sigma_{\delta} \frac{\phi(h(x))}{\Phi(h(x))[1-\Phi(h(x))]}\right\} \\
& =\left\{\rho_{0 v} \sigma_{0}+[1-\Phi(h(x))] \rho_{\delta v} \sigma_{\delta}\right\}\left\{\frac{\phi(h(x))}{\Phi(h(x))[1-\Phi(h(x))]}\right\} .
\end{aligned}
$$

where $p(x)=\Phi(h(x)), \delta=\varepsilon_{1}-\varepsilon_{0}$ (i.e., individual-specific, unobserved gains from treatment), and $\rho_{\delta u}$ is the correlation between $\delta$ and $v$.

To minimize the bias, Millimet and Tchernis (2008) propose to estimate (3) using only observations 
with a propensity score in a neighborhood around $p^{*}$, the value of the propensity score that minimizes (4). Formally, the authors propose the following minimum biased estimator of the ATE:

$$
\hat{\tau}_{M B}\left[p^{*}\right]=\left[\sum_{i \in \Omega} \frac{y_{i} D_{i}}{\widehat{p}\left(x_{i}\right)} / \sum_{i \in \Omega} \frac{D_{i}}{\widehat{p}\left(x_{i}\right)}\right]-\left[\sum_{i \in \Omega} \frac{y_{i}\left(1-D_{i}\right)}{1-\widehat{p}\left(x_{i}\right)} / \sum_{i \in \Omega} \frac{\left(1-D_{i}\right)}{1-\widehat{p}\left(x_{i}\right)}\right]
$$

where

$$
\Omega=\left\{i \mid \widehat{p}\left(x_{i}\right) \in C\left(p^{*}\right)\right\},
$$

and $C(p)$ denotes a neighborhood around $p$. We define $C\left(p^{*}\right)$ as

$$
C\left(p^{*}\right)=\left\{\widehat{p}\left(x_{i}\right) \mid \widehat{p}\left(x_{i}\right) \in(\underline{p}, \bar{p})\right\}
$$

where $\underline{p}=\max \left\{0.02, p^{*}-\alpha_{\theta}\right\}, \bar{p}=\min \left\{0.98, p^{*}+\alpha_{\theta}\right\}$, and $\alpha_{\theta}>0$ is the smallest value such that at least $\theta$ percent of both the treatment and control groups are contained in $\Omega$. In the analysis, we set $\theta=0.01,0.03,0.05,0.10$, and 0.25 . For example, if $\theta=0.01$, we find the smallest value, $\alpha_{0.01}$, such that $1 \%$ of the treatment group and $1 \%$ of the control group have a propensity score in the interval $(\underline{p}, \bar{p})$. Thus, smaller values of $\theta$ should reduce the bias at the expense of higher variance. ${ }^{7}$

To implement this technique, $p^{*}$ must be estimated. The procedure in Millimet and Tchernis (2008) calls for estimating $p^{*}$ assuming (A1), (A2), and functional forms for $g_{0}(x), g_{1}(x)$, and $h(x)$ using the Heckman bivariate normal (BVN) selection model. Specifically, assuming

$$
\begin{aligned}
& g_{0}(x)=x \beta_{0} \\
& g_{1}(x)=x \beta_{1} \\
& h(X)=x \lambda
\end{aligned}
$$

then

$$
y_{i}=x_{i} \beta_{0}+x_{i} D_{i}\left(\beta_{1}-\beta_{0}\right)+\beta_{\lambda 0}\left(1-D_{i}\right)\left[\frac{-\phi\left(x_{i} \lambda\right)}{1-\Phi\left(x_{i} \lambda\right)}\right]+\beta_{\lambda 1} D_{i}\left[\frac{\phi\left(x_{i} \lambda\right)}{\Phi\left(x_{i} \lambda\right)}\right]+\eta_{i}
$$

where $\phi(\cdot) / \Phi(\cdot)$ is the inverse Mills' ratio, $\eta$ is a mean zero error term, and

$$
\begin{aligned}
& \beta_{\lambda 0}=\rho_{0 v} \sigma_{0} \\
& \beta_{\lambda 1}=\rho_{0 v} \sigma_{0}+\rho_{\delta v} \sigma_{\delta} .
\end{aligned}
$$

Thus, OLS estimation of (6) after replacing $\lambda$ with an estimate obtained from a first-stage probit model yields consistent estimates of $\rho_{0 v} \sigma_{0}$ and $\rho_{\delta v} \sigma_{\delta}$. With these estimates, one can use (4) to obtain an estimate

\footnotetext{
${ }^{7}$ We trim observations with propensity scores above (below) 0.98 (0.02), regardless of the value of $\theta$, to prevent any single observations from receiving too large of a weight.
} 
of $p^{*}$. Millimet and Tchernis (2008) verify the virtues of this technique even if the functional form and distributional assumptions underlying the BVN selection model are mis-specified, and even if CIA holds. A confidence interval for the minimum biased estimate of the ATE is obtained using 200 bootstrap repetitions.

Propensity Score Matching For our final estimation technique, we estimate the ATE using propensity score matching along with Rosenbaum bounds (Rosenbaum 2002). While there exist other methods of assessing the sensitivity of PSM estimates to selection on unobservables, Rosenbaum bounds are computationally attractive and also offer an intuitively appealing measure of the way in which unobservables enter the model (Ferraro et al. 2007). To implement the matching estimator, we use kernel weighting with the normal kernel and a fixed bandwidth of 0.10 . Confidence intervals are obtained using 200 bootstrap repetitions.

To understand the Rosenbaum bounds, let $\pi_{i}$ represent the odds of student $i$ receiving the treatment (i.e., receiving private tutoring); $\pi_{i} /\left(1-\pi_{i}\right)$ is the odds ratio. Assume the log odds ratio can be expressed as a generalized function of observables, $x_{i}$, and a binary, unobserved term, $\delta_{i}$. Formally,

$$
\ln \left(\frac{\pi_{i}}{\left(1-\pi_{i}\right)}\right)=\kappa\left(x_{i}\right)+\gamma \delta_{i}
$$

Thus, the relative odds ratio of two observationally identical students is given by

$$
\frac{\frac{\pi_{i}}{\left(1-\pi_{i}\right)}}{\frac{\pi_{j}}{\left(1-\pi_{j}\right)}}=\frac{\exp \left\{\kappa\left(x_{i}\right)+\gamma \alpha_{i}\right\}}{\exp \left\{\kappa\left(x_{j}\right)+\gamma \alpha_{j}\right\}}=\exp \left\{\gamma\left(\delta_{i}-\delta_{j}\right)\right\}
$$

which differs from unity if $\gamma$ and $\alpha_{i}-\alpha_{j}$ is non-zero . Moreover, since $\alpha$ is binary, $\alpha_{i}-\alpha_{j} \in\{-1,0,1\}$, and

$$
\frac{1}{\exp \{\gamma\}} \leq \frac{\pi_{i}\left(1-\pi_{j}\right)}{\pi_{j}\left(1-\pi_{i}\right)} \leq \exp \{\gamma\}
$$

If $\Gamma \equiv \exp \{\gamma\}=1$, as it would in a randomized experiment or in non-experimental data free of bias from selection on unobservables, the model is said to be free of hidden bias; controlling for selection on observables would yield an unbiased estimate of the treatment effect. Higher values of $\Gamma$ imply an increasingly important role of unobservables in the treatment selection process. For example, $\Gamma=2$ implies that observationally identical students differ in their relative odds of treatment by a factor of two. Rosenbaum bounds use bounds on the distribution of Wilcoxen's signed rank statistic under the null of zero treatment effect using different values of $\Gamma$. This leads to bounds on the significance level of a one-sided test for no treatment effect.

\section{Results}

\subsection{Bivariate Probit Estimates}

Table 2 presents the results obtained from the constrained bivariate probit model; Tables 3 and 4 present the unconstrained estimates. Panel I in Table 2 and Table 3 contain the results using the first treatment: 
any tutoring versus no tutoring prior to the exam (denoted Tutor I). Panel II in Table 2 and Table 4 contain the results using the second treatment: tutoring expenditures of at least $\$ 1,275$ US dollars versus tutoring expenditures less than $\$ 1,275$ US dollars but greater than zero prior to the exam (denoted Tutor II).

When $\rho$ is constrained to zero, the results correspond to the estimated treatment effects under selection on only observables. In this case, we find a positive and highly statistically significant association between both treatments and the probability of university placement (Panel I: $\widehat{\tau}=0.282$, s.e. $=0.013$; Panel II: $\widehat{\tau}=0.248$, s.e. $=0.019)$. The corresponding marginal effects $(\mathrm{ME})$, evaluated at the mean, are 0.072 and 0.009 , respectively. Thus, while association is sizeable from in economic terms for the Tutor $I$ treatment, it is very modest for the Tutor II treatment.

However, as Tables 3 and 4 indicate, the unconstrained bivariate probit results suggest a sizeable amount of non-random selection. Interestingly, though, the pattern differs across the two treatments. In Table 3 , we find strong evidence of positive selection into the Tutor $I$ treatment $(\widehat{\rho}=0.373, p=0.000)$. Among students receiving private tutoring, Table 4 reveals evidence of negative selection into the Tutor II treatment $(\widehat{\rho}=-0.159, p=0.000)$. Thus, while unobservables associated with a higher likelihood of university placement are positively correlated with unobservables determining the use of any private tutoring services, unobservables associated with a higher likelihood of university placement are negatively correlated with unobservables determining expenditures on private tutoring services (conditional on positive expenditures). In other words, there is positive selection into tutoring overall, but among students receiving tutoring, there is negative selection into high expenditures on tutoring.

Prior to assessing the impact of this selection on our ability to interpret the estimates obtained under selection on only observables in a causal manner, a brief examination of the remaining coefficient estimates in Tables 3 and 4 is informative. In terms of explaining treatment assignment, we find that many of the variables are highly statistically significant predictors of both treatments. First, as expected given our discussion in the Introduction, students from more affluent households as measured family income, internet access, parental education, and fewer siblings are more likely to utilize private tutoring. In addition, conditional on positive expenditures, expenditures are increasing with internet access, mother's education, and family income. Second, high expenditure on private tutoring (conditional on positive expenditures), and any tutoring to a lesser extent, are more common in larger, urban environments. Third, females are less likely to receive any private tutoring. However, conditional on receiving some private tutoring, households are more likely to spend greater amounts on tutoring for females. Finally, while tutoring and tutoring expenditures are unrelated to primary school test score, students scoring better on the secondary school test are more likely to receive tutoring prior to the university placement exam; secondary school test score is unrelated to expenditures conditional on receiving tutoring. Given these patterns, if private tutoring matters for university placement, policymakers and researchers ought to be concerned about the equity implications - particularly along economic and gender lines - of a large-scale tutoring system in Turkey.

Returning now to the constrained bivariate probit results, we assess the implications of varying degrees of 
positive selection into the Tutor I treatment in Panel I of Table 2. While the unconstrained estimates yield an estimate of $\widehat{\rho}=0.373$, the constrained results indicate that even a more modest amount of positive selection on unobservables is sufficient to eliminate and even reverse the sign of the treatment effect. Specifically, when $\rho=0.10$, the estimated treatment effect is reduced by over $60 \%(\widehat{\tau}=0.106$, s.e. $=0.013)$, although the marginal effect is unchanged $(\mathrm{ME}=0.072)$. Setting $\rho=0.20$, we find a negative and statistically significant effect of tutoring on university placement $(\widehat{\tau}=-0.075$, s.e. $=0.013 ; \mathrm{ME}=-0.022)$. In the unconstrained estimation, $\rho=0.373$ and the treatment effect falls to -0.397 (s.e. $=0.124$ ); the ME is -0.124 . In light of these results, we conclude that the causal effect of any tutoring (versus no tutoring at all) is not robust, and admitting even modest levels of positive selection into tutoring is sufficient to conclude that private tutoring has a negligible or even a deleterious causal effect on university placement.

Panel II of Table 2 assesses the implications of varying degrees of negative selection into the Tutor II treatment. Given the positive coefficient obtained when $\rho$ is constrained to zero, the effect only becomes larger when one allows for negative selection. In the unconstrained estimation, $\rho=-0.158$ and the treatment effect rises to 0.532 (s.e. $=0.110$ ), implying a ME of 0.019. Thus, in contrast to Panel I, we find - among those utilizing private tutoring - greater expenditures on tutoring have a positive and robust causal effect on university placement, although the magnitude is perhaps not overly large.

Combining the two sets of results, along with the summary statistics, indicates that the majority of students utilize tutoring, but spend less than $\$ 1,275$ US dollars. Purchasing relatively low cost or short-term tutoring, however, at best has no impact on the probability of university placement, and at worst reduces the probability. However, for the small minority of students who use tutoring more intensively and/or purchase relatively expensive tutoring, such tutoring improves the probability of university placement. Since students from wealthy households with well-educated mothers are the primary recipients of large expenditures on private tutoring, the equity implications discussed previously are magnified. We now turn to the seminonparametric methods to see if this finding continues to hold.

\section{$3.2 \quad$ Propensity Score-Based Estimates}

\subsubsection{Minimum Biased Weighting Estimates}

Table 5 presents the results obtained using the Hirano and Imbens (2001) weighting estimator. In terms of the first treatment, Tutor I, the Hirano and Imbens estimator applied to the entire sample indicates that tutoring is associated with a statistically significant $10 \%$ increase in the probability of university placement $\left(\tau_{H I}=0.099\right)$. However, minimizing the bias by restricting the sample to one percent of the treatment and control groups around the estimated bias-minimizing propensity score, $p^{*}$, of 0.923 increases the point estimate in contrast to our expectation from the parametric results $\left(\tau_{M B, 0.01}=0.118\right)$. However, the effect is only marginally statistically significant as the $90 \%$ confidence level just excludes zero. While the lack of statistical significance may partly reflect the reduction in sample size, the estimation sample still includes 
nearly 2,000 students. Lastly, the Heckman BVN results are consonant with the pattern of selection discussed previously, although the estimated coefficients on the selection terms are not statistically significant.

In terms of the second treatment, Tutor II, the Hirano and Imbens estimator applied to the entire sample indicates that tutoring is associated with a statistically significant $7 \%$ increase in the probability of university placement $\left(\tau_{H I}=0.072\right)$. However, minimizing the bias by restricting the sample to one percent of the treatment and control groups around the estimated bias-minimizing propensity score of 0.855 increases the estimate $\left(\tau_{M B, 0.01}=0.091\right)$, and the effect remains statistically significant. In addition, the Heckman BVN results indicate positive and statistically significant selection into treatment on the basis of individual-specific, unobserved gains from treatment, but negative and statistically significant selection on the basis of unobservables that affect university placement absent the treatment. This pattern suggests that, ceteris paribus, students with a lower probability of university placement absent large expenditures on private tutoring, but who benefit the most from such large expenditures, are more likely to spend a large amount on tutoring. Overall, the minimum bias approach applied to the Tutor II treatment indicates, as in the parametric approach, that negative selection overall biases down the estimated treatment effect.

\subsubsection{Matching Estimates}

Table 6 presents the final estimates, obtained utilizing kernel matching and Rosenbaum bounds. Panel I reveals a statistically significant, estimated ATE of the Tutor I treatment of $8 \%(\tau=0.084)$, similar to the point estimate of the weighting estimator obtained under CIA. However, the Rosenbaum bounds reveal the lack of robustness of this estimate. Under a modest amount of positive selection on unobservables - such that observationally identical students differ in their relative odds of treatment by a factor of roughly 1.5 , we fail to reject the null that the ATE is zero. Panel II reveals a statistically significant, estimated ATE of the Tutor II treatment of $9 \%(\tau=0.093)$. Again, this is similar, as expected, to the point estimate of the weighting estimator obtained under CIA. Since negative selection only serves to strengthen the beneficial effect of greater spending, conditional on receiving any tutoring, the Rosenbaum bounds are uninformative in this case; they simply indicate that we continue to reject the null that the ATE is zero as we allow for increasingly strong negative selection.

\subsection{Further Analysis}

To assess the robustness of our conclusions, we perform two sets of additional analyses. ${ }^{8}$ First, we re-visit the issue of non-random missing data for the Tutor II treatment. Ideally one would have an exclusion restriction - a variable impacting the probability of having non-missing data that does not impact the probability of university placement conditional on the remaining regressors - enabling the estimation of Heckman selection model. However, such a variable is unlikely to exist in our data. Nonetheless, to get an idea of how the missing data impacts our results, we assume that all students who report utilizing some tutoring, but with

\footnotetext{
${ }^{8}$ All results in this section are available upon request.
} 
missing data on the exact amount spent on tutoring, spent less than $\$ 1,275$ US dollars. In other words, we replace missing values for Tutor II with zero. As discussed above, since students with missing data come from less affluent households in more rural areas, and these attributes are negatively associated with expenditures in Table 4, replacing missing values with zero may not be far off the mark.

Proceeding along these lines, we repeat all of the previous estimations. In the interest of brevity, we simply summarize the results. First, the bivariate probit results, conditional on $\rho$, are qualitatively unchanged. However, the unconstrained bivariate probit model yields $\widehat{\rho}=-0.006(p=0.904)$, indicating a failure to reject exogeneity. Under the assumption of exogeneity, the treatment effect is $\widehat{\tau}=0.278$ (s.e. $=0.019$; ME $=0.005)$, which is similar to the estimate under exogeneity in Panel II of Table 2 .

Second, the semi-nonparametric results replacing missing values of Tutor II with zero are also essentially unchanged. If anything, the estimates indicate a slightly larger impact of high expenditures on university placement. In sum, assuming that individuals with missing data spent less than $\$ 1,275$ US dollars does not alter our conclusion that high spending on private tutoring has a beneficial causal effect on university placement conditional on using any tutoring.

Our second set of additional analyses allows the impact of private tutoring to differ along observable dimensions. Specifically, we repeat the previous analysis - of both the Tutor I and Tutor II treatments for different sub-groups of students. First, we split the sample along gender lines. Second, we divided the sample into those with internet access and those without. Our conclusions regarding the impact of private tutoring did not qualitatively differ along these dimensions.

\section{Conclusion}

In this paper, we study the determinants and impacts of private tutoring in Turkey using a unique crosssectional survey from 2002. Given our prior belief that selection into tutoring is non-random, but lacking a valid exclusion restriction, we employ recently developed estimation techniques from the program evaluation literature that assess the sensitivity of estimates obtained under conditional independence to selection on unobservables. Our results are striking, and should provide cause for alarm by policymakers already wary of the burgeoning market for private tutoring. Specifically, we reach three conclusions. First, while the use of private tutoring is positively associated with university placement, this appears entirely explained by positive selection. Moreover, allowing for even a modest amount of positive selection on unobservables indicates that, on average, tutoring actually decreases the probability of university placement. Second, there is a robust, positive causal effect of tutoring - among those utilizing tutoring - on the probability of university placement if students spend a relatively large amount on tutoring (in excess of $\$ 1,275$ US dollars). In combination, then, the results suggest that unless one is willing to invest heavily in private tutoring, one is better off forsaking any tutoring. Finally, we find that the present utilization of private tutoring has potentially large implications on intergenerational income mobility and regional income disparities in Turkey. While tutoring 
in general is extremely prevalent in Turkey, only the affluent residing in major urban areas are likely to spend sufficiently to reap the rewards. 


\section{References}

[1] Altonji, J.G., T.E. Elder, and C.R. Taber (2005), "Selection on Observed and Unobserved Variables: Assessing the Effectiveness of Catholic Schools," Journal of Political Economy, 113, 151-184.

[2] Altonji, J.G., T.E. Elder, and C.R. Taber (2008), "Using Selection on Observed Variables to Assess Bias from Unobservables when Evaluating Swan-Ganz Catheterization," American Economic Review, $98,345-350$.

[3] Aurini, J. and S. Davies (2003), "The Transformation of Private Tutoring: Education in a Franchise Form." Submission for the Annual Meetings of the CSAA Halifax.

[4] Black, D.A. and J.A. Smith (2004), "How Robust is the Evidence on the Effects of College Quality? Evidence from Matching," Journal of Econometrics, 121, 99-124.

[5] Bray, M. (1999), "The Shadow Education System: Private Tutoring and Its Implications for Planners," Fundamentals of Educational Planning No. 61, Paris: UNESCO International Institute for Educational Planning (IIEP).

[6] Bray, M. and P. Kwok (2003), "Demand for Private Supplementary Tutoring: Conceptual Considerations and Socio-Economic Patterns." Economics of Education Review, 22, 611-620.

[7] Dang, H.-A. (2007a), "The Determinants and Impact of Private Tutoring Classes in Vietnam," unpublished Ph.D. dissertation, University of Minnesota.

[8] Dang, H.A. (2007b), "The Determinants and Impact of Private Tutoring Classes in Vietnam," Economics of Education Review, 26, 684-699.

[9] Dang, H.A. and D. Halsey Rogers (2008), "How to Interpret the Growing Phenomenon of Private Tutoring: Human Capital Deepening, Inequality Increasing or Waster of Resources?" Policy Research Working Paper, World Bank.

[10] Ferraro, P.J., C. McIntosh, and M. Ospina (2007), "The Effectiveness of the US Endangered Species Act: An Econometric Analysis Using Matching Methods," Journal of Environmental Economics and Management, 54, 245-261.

[11] Fisher, R.A. (1935), The Design of Experiments, Edinburgh: Oliver \& Boyd.

[12] Hirano, K. and Imbens, G.W. (2001), "Estimation of Causal Effects using Propensity Score Weighting: An Application to Data on Right Heart Catheterization," Health Services and Outcomes Research Methodology, 2, 259-278.

[13] Kang, C. (2007), "Does Money Matter? The Effect of Private Educational Expenditures on Academic Performance," National University of Singapore, Department of Economics Working Paper No. 0704. 
[14] Kim. S. and J.-H. Lee (2004), "Private Tutoring and Demand for Education in South Korea," unpublished manuscript, University of Wisconsin-Milwaukee.

[15] Millimet, D.L. and R. Tchernis (2008), "Minimizing Bias in Selection on Observables Estimators when Unconfoundedness Fails," unpublished manuscript, Southern Methodist University.

[16] Neyman, J. (1923), "On the Application of Probability Theory to Agricultural Experiments. Essay on Principles. Section 9," translated in Statistical Science, (with discussion), 5, 465-480, (1990).

[17] Rosenbaum, P.R. (2002), Observational Studies, Second Edition. New York: Springer.

[18] Roy, A.D. (1951), "Some Thoughts on the Distribution of Income," Oxford Economic Papers, 3, 135-146.

[19] Rubin, D. (1974), "Estimating Causal Effects of Treatments in Randomized and Non-randomized Studies," Journal of Educational Psychology, 66, 688-701.

[20] Stevenson, D.L. and D.P. Baker (1992), "Shadow Education and Allocation in Formal Schooling: Transition to University in Japan," American Journal of Sociology, 97, 1639-57

[21] Tansel, A. and F. Bircan (2005), "Effect of Private Tutoring on University Entrance Examination Performance in Turkey," IZA Discussion Paper No. 1609.

[22] Tansel, A. and F. Bircan (2006), "Demand for Education in Turkey: A Tobit Analysis of Private Tutoring Expenditures," Economics of Education Review, 25, 303-313.

[23] Tansel, A. and F. Bircan (2008), "Private Supplementary Tutoring in Turkey: Recent Evidence on Its Various Aspects," IZA Discussion Paper No. 3471. 


\begin{tabular}{|c|c|c|c|c|c|c|c|c|c|c|c|}
\hline \multirow[b]{2}{*}{ Variable } & \multicolumn{3}{|c|}{ Full Sample } & \multicolumn{3}{|c|}{ Tutor II Missing } & \multicolumn{3}{|c|}{ Tutor II Non-Missing } & \multirow[b]{2}{*}{ Diff } & \multirow[b]{2}{*}{ P-value } \\
\hline & $\mathbf{N}$ & Mean & SD & $\mathbf{N}$ & Mean & SD & $\mathbf{N}$ & Mean & SD & & \\
\hline $\begin{array}{l}\text { University Placement } \\
\text { (1 = Yes })\end{array}$ & 90,410 & 0.280 & 0.449 & 26,124 & 0.212 & 0.409 & 46,262 & 0.364 & 0.481 & -0.151 & 0.000 \\
\hline Tutor I (1 = Yes) & 90,410 & 0.801 & 0.400 & 26,124 & 1.000 & 0.000 & 46,262 & 1.000 & 0.000 & & \\
\hline $\begin{array}{l}\text { Tutor II ( } 1=\$ 1,275+ \\
\text { US dollars, } 0=\text { between } \$ 1 \\
\text { and } \$ 1,275 \text { US dollars) }\end{array}$ & 46,262 & 0.131 & 0.337 & & & & 46,262 & 0.131 & 0.337 & & \\
\hline Female $(1=$ Yes $)$ & 90,410 & 0.451 & 0.498 & 26,124 & 0.433 & 0.495 & 46,262 & 0.457 & 0.498 & -0.024 & 0.000 \\
\hline Internet Access (1 = Yes) & 90,410 & 0.379 & 0.485 & 26,124 & 0.300 & 0.458 & 46,262 & 0.467 & 0.499 & -0.167 & 0.000 \\
\hline \multicolumn{12}{|l|}{ Number of Siblings } \\
\hline Less than or Equal to Two & 90,410 & 0.320 & 0.467 & 26,124 & 0.215 & 0.411 & 46,262 & 0.428 & 0.495 & -0.213 & 0.000 \\
\hline Three & 90,410 & 0.266 & 0.442 & 26,124 & 0.259 & 0.438 & 46,262 & 0.275 & 0.446 & -0.015 & 0.000 \\
\hline Four & 90,410 & 0.163 & 0.370 & 26,124 & 0.193 & 0.394 & 46,262 & 0.134 & 0.341 & 0.059 & 0.000 \\
\hline Five or More & 90,410 & 0.249 & 0.432 & 26,124 & 0.330 & 0.470 & 46,262 & 0.163 & 0.369 & 0.168 & 0.000 \\
\hline \multicolumn{12}{|l|}{ Mother's Education } \\
\hline Illiterate & 90,410 & 0.188 & 0.390 & 26,124 & 0.256 & 0.436 & 46,262 & 0.118 & 0.322 & 0.138 & 0.000 \\
\hline Literate or Primary School & 90,410 & 0.525 & 0.499 & 26,124 & 0.563 & 0.496 & 46,262 & 0.482 & 0.500 & 0.080 & 0.000 \\
\hline Seconday School & 90,410 & 0.065 & 0.247 & 26,124 & 0.050 & 0.217 & 46,262 & 0.079 & 0.270 & -0.030 & 0.000 \\
\hline High School & 90,410 & 0.109 & 0.312 & 26,124 & 0.056 & 0.229 & 46,262 & 0.165 & 0.371 & -0.109 & 0.000 \\
\hline Higher Education & 90,410 & 0.055 & 0.229 & 26,124 & 0.020 & 0.140 & 46,262 & 0.094 & 0.292 & -0.074 & 0.000 \\
\hline \multicolumn{12}{|l|}{ Father's Education } \\
\hline Illiterate & 90,410 & 0.034 & 0.180 & 26,124 & 0.051 & 0.219 & 46,262 & 0.018 & 0.131 & 0.033 & 0.000 \\
\hline Literate or Primary School & 90,410 & 0.427 & 0.495 & 26,124 & 0.513 & 0.500 & 46,262 & 0.335 & 0.472 & 0.177 & 0.000 \\
\hline Seconday School & 90,410 & 0.125 & 0.330 & 26,124 & 0.129 & 0.335 & 46,262 & 0.118 & 0.323 & 0.010 & 0.000 \\
\hline High School & 90,410 & 0.181 & 0.385 & 26,124 & 0.140 & 0.347 & 46,262 & 0.221 & 0.415 & -0.081 & 0.000 \\
\hline Higher Education & 90,410 & 0.149 & 0.356 & 26,124 & 0.076 & 0.265 & 46,262 & 0.227 & 0.419 & -0.151 & 0.000 \\
\hline \multicolumn{12}{|l|}{ Primary School Score } \\
\hline Good (4 out of 4$)$ & 90,410 & 0.715 & 0.451 & 26,124 & 0.624 & 0.484 & 46,262 & 0.800 & 0.400 & -0.176 & 0.000 \\
\hline $\operatorname{Bad}(1,2,3$ out of 4$)$ & 90,410 & 0.254 & 0.435 & 26,124 & 0.328 & 0.470 & 46,262 & 0.179 & 0.383 & 0.150 & 0.000 \\
\hline \multicolumn{12}{|l|}{ Secondary School Score } \\
\hline Good (4 out of 4) & 90,410 & 0.235 & 0.424 & 26,124 & 0.165 & 0.371 & 46,262 & 0.303 & 0.460 & -0.138 & 0.000 \\
\hline Mediocre (3 out of 4) & 90,410 & 0.450 & 0.497 & 26,124 & 0.444 & 0.497 & 46,262 & 0.449 & 0.497 & -0.006 & 0.149 \\
\hline Bad (1 or 2 out of 4$)$ & 90,410 & 0.275 & 0.447 & 26,124 & 0.337 & 0.473 & 46,262 & 0.215 & 0.411 & 0.122 & 0.000 \\
\hline \multicolumn{12}{|l|}{ Income (monhly) } \\
\hline Group 1 (Less than $\$ 160$ ) & 90,410 & 0.249 & 0.432 & 26,124 & 0.297 & 0.457 & 46,262 & 0.198 & 0.398 & 0.099 & 0.000 \\
\hline $\begin{array}{l}\text { Group } 2 \text { (Between } \$ 160 \\
\text { and } \$ 320 \text { ) }\end{array}$ & 90,410 & 0.117 & 0.322 & 26,124 & 0.102 & 0.303 & 46,262 & 0.129 & 0.336 & -0.027 & 0.000 \\
\hline $\begin{array}{l}\text { Group } 3 \text { (Between \$320 } \\
\text { and \$480) }\end{array}$ & 90,410 & 0.253 & 0.435 & 26,124 & 0.216 & 0.411 & 46,262 & 0.284 & 0.451 & -0.068 & 0.000 \\
\hline Group 4 (More than $\$ 480$ ) & 90,410 & 0.296 & 0.457 & 26,124 & 0.266 & 0.442 & 46,262 & 0.328 & 0.469 & -0.062 & 0.000 \\
\hline \multicolumn{12}{|l|}{ Population } \\
\hline Group 1 (Less than 50,000) & 90,410 & 0.385 & 0.487 & 26,124 & 0.486 & 0.500 & 46,262 & 0.270 & 0.444 & 0.216 & 0.000 \\
\hline $\begin{array}{l}\text { Group } 2 \text { (Between 50,000 } \\
\text { and 100,000) }\end{array}$ & 90,410 & 0.398 & 0.489 & 26,124 & 0.377 & 0.485 & 46,262 & 0.425 & 0.494 & -0.047 & 0.000 \\
\hline $\begin{array}{l}\text { Group } 3 \text { (Between 100,000 } \\
\text { and 1,000,000) }\end{array}$ & 90,410 & 0.120 & 0.325 & 26,124 & 0.077 & 0.267 & 46,262 & 0.165 & 0.371 & -0.088 & 0.000 \\
\hline Group 4 (More than 1,000,000) & 90,410 & 0.083 & 0.275 & 26,124 & 0.037 & 0.190 & 46,262 & 0.130 & 0.336 & -0.093 & 0.000 \\
\hline
\end{tabular}

Notes: $\mathrm{N}$ = number of observations; $\mathrm{SD}=$ standard deviation. Diff is difference in means across Tutor II missing and non-missing samples; p-value is from corresponding t-test of equality of means. 


\section{Coefficient}

(Standard Error)

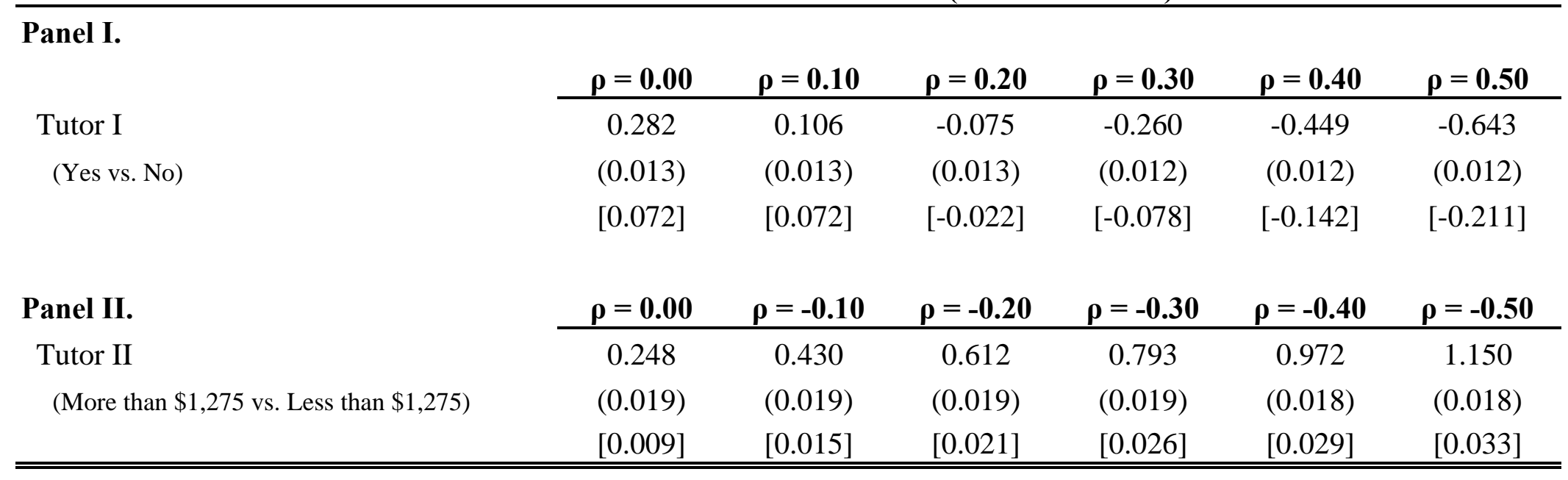

Notes: Standard errors in parentheses; marginal effects evaluated at the mean in brackets. 
Table 3. Unconstrained Bivariate Probit Results: Tutor I Treatment

\begin{tabular}{|c|c|c|c|c|c|c|}
\hline & \multicolumn{3}{|c|}{ Outcome } & \multicolumn{3}{|c|}{ Treatment Assignment } \\
\hline & Coeff & S.E. & P-value & Coeff & S.E. & P-value \\
\hline \multirow[t]{2}{*}{ Tutor I (Yes vs. No) } & -0.397 & 0.124 & 0.001 & & & \\
\hline & {$[-0.124]$} & & & & & \\
\hline Female $(1=$ Yes $)$ & -0.050 & 0.010 & 0.000 & -0.089 & 0.010 & 0.000 \\
\hline Internet Access $(1=$ Yes $)$ & 0.160 & 0.010 & 0.000 & 0.139 & 0.011 & 0.000 \\
\hline \multicolumn{7}{|l|}{ Number of Siblings } \\
\hline Less than of Equal to Two & 0.208 & 0.117 & 0.077 & -0.099 & 0.129 & 0.441 \\
\hline Three & 0.139 & 0.118 & 0.236 & -0.221 & 0.129 & 0.087 \\
\hline Four & 0.072 & 0.118 & 0.539 & -0.319 & 0.129 & 0.013 \\
\hline Five or More & 0.014 & 0.118 & 0.904 & -0.377 & 0.129 & 0.003 \\
\hline \multicolumn{7}{|l|}{ Mother's Education } \\
\hline Illiterate & -0.065 & 0.031 & 0.036 & -0.107 & 0.031 & 0.001 \\
\hline Literate or Primary School & 0.015 & 0.031 & 0.620 & -0.071 & 0.032 & 0.024 \\
\hline Seconday School & 0.046 & 0.035 & 0.183 & -0.019 & 0.037 & 0.615 \\
\hline High School & 0.160 & 0.034 & 0.000 & 0.206 & 0.037 & 0.000 \\
\hline Higher Education & 0.279 & 0.037 & 0.000 & 0.417 & 0.050 & 0.000 \\
\hline \multicolumn{7}{|l|}{ Father's Education } \\
\hline Illiterate & -0.052 & 0.037 & 0.157 & -0.083 & 0.034 & 0.015 \\
\hline Literate or Primary School & 0.028 & 0.026 & 0.293 & -0.106 & 0.026 & 0.000 \\
\hline Seconday School & 0.022 & 0.029 & 0.452 & -0.097 & 0.029 & 0.001 \\
\hline High School & 0.059 & 0.028 & 0.035 & -0.008 & 0.028 & 0.777 \\
\hline Higher Education & 0.219 & 0.029 & 0.000 & 0.172 & 0.032 & 0.000 \\
\hline \multicolumn{7}{|l|}{ Primary School Score } \\
\hline Good (4 out of 4$)$ & 0.345 & 0.044 & 0.000 & 0.053 & 0.047 & 0.257 \\
\hline $\operatorname{Bad}(1,2,3$ out of 4$)$ & 0.144 & 0.045 & 0.001 & -0.034 & 0.047 & 0.468 \\
\hline \multicolumn{7}{|l|}{ Secondary School Score } \\
\hline Good (4 out of 4$)$ & 0.282 & 0.038 & 0.000 & 0.114 & 0.044 & 0.009 \\
\hline Mediocre (3 out of 4 ) & -0.092 & 0.038 & 0.015 & -0.086 & 0.043 & 0.044 \\
\hline $\operatorname{Bad}(1$ or 2 out of 4$)$ & -0.195 & 0.038 & 0.000 & -0.195 & 0.043 & 0.000 \\
\hline \multicolumn{7}{|l|}{ Income (monhly) } \\
\hline Group 1 (Less than $\$ 160)$ & 0.031 & 0.041 & 0.441 & -0.213 & 0.041 & 0.000 \\
\hline Group 2 (Between $\$ 160$ and $\$ 320$ ) & 0.089 & 0.040 & 0.028 & -0.026 & 0.041 & 0.533 \\
\hline Group 3 (Between $\$ 320$ and $\$ 480$ ) & 0.146 & 0.042 & 0.000 & 0.116 & 0.044 & 0.008 \\
\hline Group 4 (More than $\$ 480$ ) & 0.272 & 0.043 & 0.000 & 0.291 & 0.047 & 0.000 \\
\hline \multicolumn{7}{|l|}{ Population } \\
\hline Group 1 (Less than 50,000 ) & 0.116 & 0.020 & 0.000 & -0.059 & 0.019 & 0.002 \\
\hline Group 2 (Between 50,000 and 100,000) & 0.199 & 0.022 & 0.000 & 0.087 & 0.022 & 0.000 \\
\hline Group 3 (Between 100,000 and 1,000,000) & 0.209 & 0.019 & 0.000 & 0.085 & 0.019 & 0.000 \\
\hline Group 4 (More than $1,000,000$ ) & 0.326 & 0.019 & 0.000 & -0.032 & 0.019 & 0.093 \\
\hline$\rho$ & \multicolumn{6}{|c|}{$0.373[\mathrm{p}=0.000]$} \\
\hline Number of Observations & \multicolumn{6}{|c|}{90,410} \\
\hline
\end{tabular}

Note: Tutor I treatment is one for students utilizing any private tutoring, zero otherwise. Marginal effect for treatment effect in brackets. 
Table 4. Unconstrained Bivariate Probit Results: Tutor II Treatment

\begin{tabular}{|c|c|c|c|c|c|c|}
\hline & \multicolumn{3}{|c|}{ Outcome } & \multicolumn{3}{|c|}{ Treatment Assignment } \\
\hline & Coeff & S.E. & P-value & Coeff & S.E. & P-value \\
\hline \multirow[t]{2}{*}{ Tutor II $(\$ 1,275+$ vs. $<\$ 1,275)$} & 0.532 & 0.110 & 0.000 & & & \\
\hline & [0.019] & & & & & \\
\hline Female ( 1 = Yes $)$ & -0.042 & 0.013 & 0.001 & 0.067 & 0.017 & 0.000 \\
\hline Internet Access $(1=$ Yes $)$ & 0.103 & 0.013 & 0.000 & 0.160 & 0.017 & 0.000 \\
\hline \multicolumn{7}{|l|}{ Number of Siblings } \\
\hline Less than of Equal to Two & 0.104 & 0.171 & 0.542 & -0.071 & 0.214 & 0.739 \\
\hline Three & 0.079 & 0.171 & 0.642 & -0.242 & 0.214 & 0.260 \\
\hline Four & 0.048 & 0.171 & 0.779 & -0.310 & 0.215 & 0.150 \\
\hline Five or More & -0.038 & 0.171 & 0.823 & -0.207 & 0.215 & 0.337 \\
\hline \multicolumn{7}{|l|}{ Mother's Education } \\
\hline Illiterate & -0.037 & 0.045 & 0.412 & -0.183 & 0.064 & 0.004 \\
\hline Literate or Primary School & 0.033 & 0.044 & 0.454 & -0.184 & 0.060 & 0.002 \\
\hline Seconday School & 0.014 & 0.048 & 0.777 & -0.103 & 0.065 & 0.114 \\
\hline High School & 0.079 & 0.046 & 0.086 & 0.072 & 0.062 & 0.245 \\
\hline Higher Education & 0.176 & 0.049 & 0.000 & 0.135 & 0.064 & 0.035 \\
\hline \multicolumn{7}{|l|}{ Father's Education } \\
\hline Illiterate & -0.023 & 0.062 & 0.710 & 0.103 & 0.093 & 0.272 \\
\hline Literate or Primary School & 0.040 & 0.039 & 0.310 & -0.002 & 0.055 & 0.976 \\
\hline Seconday School & 0.032 & 0.042 & 0.445 & -0.021 & 0.059 & 0.720 \\
\hline High School & 0.044 & 0.040 & 0.278 & 0.061 & 0.056 & 0.280 \\
\hline Higher Education & 0.178 & 0.041 & 0.000 & 0.041 & 0.057 & 0.473 \\
\hline \multicolumn{7}{|l|}{ Primary School Score } \\
\hline Good (4 out of 4) & 0.359 & 0.062 & 0.000 & 0.074 & 0.079 & 0.347 \\
\hline $\operatorname{Bad}(1,2,3$ out of 4$)$ & 0.172 & 0.064 & 0.007 & 0.002 & 0.082 & 0.982 \\
\hline \multicolumn{7}{|l|}{ Secondary School Score } \\
\hline Good (4 out of 4) & 0.241 & 0.050 & 0.000 & -0.102 & 0.063 & 0.104 \\
\hline Mediocre (3 out of 4 ) & -0.117 & 0.049 & 0.018 & -0.021 & 0.062 & 0.732 \\
\hline $\operatorname{Bad}(1$ or 2 out of 4$)$ & -0.251 & 0.050 & 0.000 & 0.036 & 0.064 & 0.567 \\
\hline \multicolumn{7}{|l|}{ Income (monhly) } \\
\hline Group 1 (Less than $\$ 160)$ & 0.129 & 0.062 & 0.039 & -0.496 & 0.075 & 0.000 \\
\hline Group 2 (Between $\$ 160$ and $\$ 320$ ) & 0.106 & 0.062 & 0.086 & -0.316 & 0.073 & 0.000 \\
\hline Group 3 (Between $\$ 320$ and $\$ 480$ ) & 0.083 & 0.063 & 0.182 & 0.021 & 0.074 & 0.777 \\
\hline Group 4 (More than $\$ 480$ ) & 0.120 & 0.067 & 0.075 & 0.565 & 0.074 & 0.000 \\
\hline \multicolumn{7}{|l|}{ Population } \\
\hline Group 1 (Less than 50,000) & 0.154 & 0.030 & 0.000 & -0.147 & 0.040 & 0.000 \\
\hline Group 2 (Between 50,000 and 100,000) & 0.194 & 0.031 & 0.000 & -0.205 & 0.043 & 0.000 \\
\hline Group 3 (Between 100,000 and 1,000,000) & 0.193 & 0.029 & 0.000 & -0.099 & 0.037 & 0.008 \\
\hline Group 4 (More than $1,000,000$ ) & 0.318 & 0.029 & 0.000 & 0.269 & 0.036 & 0.000 \\
\hline$\rho$ & \multicolumn{6}{|c|}{$-0.159[\mathrm{p}=0.000]$} \\
\hline Number of Observations & \multicolumn{6}{|c|}{46,262} \\
\hline
\end{tabular}

Note: Tutor II treatment is one for students utilizing more than \$1,275 US dollars of private tutoring, zero otherwise. Sample is restricted to those utilizing private tutoring. Marginal effect for treatment effect in brackets. 
Table 5. Minimum Bias Propensity Score Results

\begin{tabular}{|c|c|c|}
\hline & $\begin{array}{c}\text { Tutor I } \\
\text { (Yes vs. No) } \\
\end{array}$ & $\begin{array}{c}\text { Tutor II } \\
(\$ 1,275+\text { vs. }<\$ 1,275)\end{array}$ \\
\hline$\tau_{\mathrm{HI}}$ & $\begin{array}{c}0.099 \\
{[0.091,0.106]}\end{array}$ & $\begin{array}{c}0.072 \\
{[0.057,0.087]}\end{array}$ \\
\hline$\tau_{M B, 0.25}$ & $\begin{array}{c}0.141 \\
{[0.036,0.144]}\end{array}$ & $\begin{array}{c}0.113 \\
{[0.091,0.125]}\end{array}$ \\
\hline$\tau_{\mathrm{MB}, \mathbf{0 . 1 0}}$ & $\begin{array}{c}0.148 \\
{[0.023,0.153]}\end{array}$ & $\begin{array}{c}0.108 \\
{[0.084,0.125]}\end{array}$ \\
\hline$\tau_{\mathrm{MB}, \mathbf{0 . 0 5}}$ & $\begin{array}{c}0.159 \\
{[0.019,0.165]}\end{array}$ & $\begin{array}{c}0.110 \\
{[0.085,0.137]}\end{array}$ \\
\hline$\tau_{\mathrm{MB}, \mathbf{0 . 0 3}}$ & $\begin{array}{c}0.167 \\
{[0.017,0.161]}\end{array}$ & $\begin{array}{c}0.126 \\
{[0.085,0.154]}\end{array}$ \\
\hline$\tau_{\mathrm{MB}, 0.01}$ & $\begin{array}{c}0.118 \\
{[0.000,0.178]}\end{array}$ & $\begin{array}{c}0.091 \\
{[0.029,0.135]}\end{array}$ \\
\hline$\rho_{0} \sigma_{0}$ & $\begin{array}{c}0.075 \\
{[-0.681,0.852]}\end{array}$ & $\begin{array}{c}-0.132 \\
{[-0.271,-0.005]}\end{array}$ \\
\hline$\rho_{\delta} \sigma_{\delta}$ & 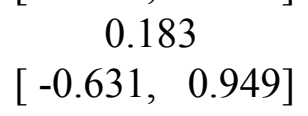 & $\begin{array}{c}0.905 \\
{[0.303,1.459]}\end{array}$ \\
\hline $\mathbf{p}^{*}$ & $\begin{array}{c}0.923 \\
{[0.078,0.975]}\end{array}$ & $\begin{array}{c}0.855 \\
{[0.624,0.980]}\end{array}$ \\
\hline
\end{tabular}

Notes: $90 \%$ empirical confidence intervals obtained using 200 bootstrap repetitions. $\mathrm{HI}=$ Hirano and Imbens (2001) normalized estimator; $\mathrm{MB}=$ minimum biased estimator using $\theta=0.25,0.10,0.05,0.03$, or 0.01 . $\mathrm{p}^{*}=$ biasminimizing propensity score. 
Table 6. Propensity Score (Kernel) Matching Estimates and Rosenbaum Bounds

\begin{tabular}{|c|c|c|c|c|c|c|c|c|c|}
\hline & ATE & $\Gamma=1$ & $\Gamma=1.2$ & $\Gamma=1.4$ & $\Gamma=1.6$ & $\Gamma=1.8$ & $\Gamma=2$ & $\Gamma=2.5$ & $\Gamma=\mathbf{3}$ \\
\hline \multicolumn{10}{|l|}{ Panel I. } \\
\hline $\begin{array}{l}\text { Tutor I } \\
\text { (Yes vs. No) }\end{array}$ & $\begin{array}{c}0.084 \\
{[0.073,0.095]}\end{array}$ & $\mathrm{p}=0.000$ & $\mathrm{p}=0.000$ & $\mathrm{p}=0.000$ & $\mathrm{p}=0.948$ & $\mathrm{p}=1.000$ & $\mathrm{p}=1.000$ & $\mathrm{p}=1.000$ & $\mathrm{p}=1.000$ \\
\hline \multicolumn{10}{|l|}{ Panel II. } \\
\hline $\begin{array}{l}\text { Tutor II } \\
(\$ 1,275+\text { vs. }<\$ 1,275)\end{array}$ & $\begin{array}{c}0.093 \\
{[0.075,0.112]}\end{array}$ & $\mathrm{p}=0.000$ & $\mathrm{p}=0.000$ & $\mathrm{p}=0.000$ & $\mathrm{p}=1.000$ & $\mathrm{p}=1.000$ & $\mathrm{p}=1.000$ & $\mathrm{p}=1.000$ & $\mathrm{p}=1.000$ \\
\hline
\end{tabular}

Notes: Matching estimates utilize the normal kernel with a fixed bandwidth of $0.10 .90 \%$ empirical confidence intervals obtained using 200 bootstrap repetitions. 